\title{
Identification of major depressive disorder among the long-term unemployed
}

\section{Nurmela, Kirsti}

2018-01

Nurmela , K, Mattila , A , Heikkinen , V , Uitti , J , Ylinen , A \& Virtanen , P 2018 , '

Identification of major depressive disorder among the long-term unemployed ', Social

Psychiatry and Psychiatric Epidemiology , vol. 53 , no. 1 , pp. 45-52 . https://doi.org/10.1007/s00127-017-1457-y

http://hdl.handle.net/10138/299130

https://doi.org/10.1007/s00127-017-1457-y

publishedVersion

Downloaded from Helda, University of Helsinki institutional repository.

This is an electronic reprint of the original article.

This reprint may differ from the original in pagination and typographic detail.

Please cite the original version. 


\title{
Identification of major depressive disorder among the long-term unemployed
}

\author{
Kirsti Nurmela ${ }^{1,2} \cdot$ Aino Mattila ${ }^{1,3} \cdot$ Virpi Heikkinen ${ }^{1,4} \cdot$ Jukka Uitti $^{5,6,7}$. \\ Aarne Ylinen $^{8,9} \cdot$ Pekka Virtanen ${ }^{1}$
}

Received: 22 February 2017 / Accepted: 27 October 2017 / Published online: 9 November 2017

c) Springer-Verlag GmbH Germany, part of Springer Nature 2017

\begin{abstract}
Purpose Depression is a common mental health disorder among the unemployed, but research on identifying their depression in health care is scarce. The present study aimed to explore the identification of major depressive disorder (MDD) in health care on long-term unemployed and find out if the duration of unemployment correlates with the risk for unidentified MDD.

Methods The study sample consisted the patient files of long-term unemployed people (duration of unemployment 1-35 years, median 11 years), who in a screening project diagnosed with MDD $(n=243)$. The MDD diagnosis was found in the health care records of 101. Binomial logistic regression models were used to explore the effect of the
\end{abstract}

Kirsti Nurmela

kirsti.nurmela@staff.uta.fi

1 Faculty of Social Sciences, University of Tampere, 33014 Tampere, Finland

2 Mental Health and Substance Abuse Services, Tampere, Finland

3 Department of Adult Psychiatry, Tampere University Hospital, Tampere, Finland

4 Department of Neurosciences and Rehabilitation, Tampere University Hospital, Tampere, Finland

5 Faculty of Medicine and Life Sciences, University of Tampere, Tampere, Finland

6 Clinic of Occupational Medicine, Tampere University Hospital, Tampere, Finland

7 Finnish Institute of Occupational Health, Tampere, Finland

8 Department of Neurological Sciences, University of Helsinki, Helsinki, Finland

9 Department of Neurology, Helsinki University Central Hospital, Helsinki, Finland duration of unemployment, as a discrete variable, to the identification of MDD in health care.

Results MDD was appropriately identified in health care for $42 \%(n=101)$ of the participants with MDD. The odds ratio for unidentified MDD in health care was 1.060 (95\% confidence interval $1.011 ; 1.111, p=0.016)$ per unemployment year. When unemployment had continued, for example, for five years the odds ratio for having unidentified MDD was 1.336 . The association remained significant throughout adjustments for the set of background factors (gender, age, occupational status, marital status, homelessness, criminal record, suicide attempts, number of health care visits).

Conclusions This study among depressed long-term unemployed people indicates that the longer the unemployment period has lasted, the more commonly these people suffer from unidentified MDD. Health services should be developed with respect to sensitivity to detect signs of depression among the long-term unemployed.

Keywords Depression - Health care - Identification . Major depressive disorder $\cdot$ Unemployment

\section{Introduction}

Major depressive disorder (MDD) causes significant human suffering and is the second leading cause of years lived with disabilities globally [1]. According to a review article the 12-month prevalence of MDD is 6.9\% [2]. Unipolar depression also is a leading contributor to a burden of disease measured by disability adjusted life years: The number of lost years of healthy life has been calculated as 4,320,400 in Europe [3, 4]. According to earlier studies around 10\% of primary health care patients $[5,6]$ and $50 \%$ of specialized mental health care patients [5] suffer from clinical 
depression. The financial burden of depression is also notable. The total costs of MDD in the USA have been estimated at over $\$ 210.5$ billion in 2010 [7]. One potentially affective means of combatting the challenges posed by MDD would be to focus the health service resources for the risk groups.

One of the most noteworthy risk groups for MDD is unemployed people. A connection between unemployment and deteriorated mental health, especially depression, has been demonstrated in several studies [8-11]. In particular, prolonged unemployment incurs a risk for depression and vice versa: poor mental health may negatively affect reemployment $[12,13]$.

The identification of depression is a key objective in improving depression remission rates. In primary care settings the depression identification rate has varied between 47 and $84 \%[14,15]$. As unemployment and depression commonly co-occur, paying attention especially to the identification of depression among unemployed people could substantially enhance the rate of identified depression as a whole. The identification of depression may, however, be more complicated among the unemployed because there are no job-related requirements regarding mental health and the need for seeking care may also be reduced.

The reasons for inadequate identification of depression among the unemployed largely lie in their particular patterns of utilization of health services. Visits to health care professionals have been demonstrated to decrease during unemployment but the results are not entirely conclusive [16-19]. At least some activity and initiative on the part of the individual concerned would have been demanded to seek professional help for mental problems but these properties are often deficient in people with mental disorders. It is known that the unemployed do not seek professional help for their health problems as actively as do employees, or even if they seek help from health care, their mental health problems and need for treatment go largely unidentified [20, 21]. In sum, there is substantial evidence of a connection between depression and unemployment. However, research on the extent to which depression among the unemployed is identified in health care is scarce.

The aim of this study was to explore the identification of depression among the long-term unemployed in health care focusing especially on the duration of unemployment. We expected to find that the risk of suffering from unidentified depression increases along with the lengthening of the unemployment spell.

\section{Materials and methods}

The study sample consisted of long-term unemployed people involved in the 'Eligibility for a Disability Pension' project (EDIPE), initiated by the Ministry of Labour in Finland
[22]. According to the above demonstrated association between deterioration of health with prolonged unemployment, the idea of the EDIPE—project was to identify from among the long-term unemployed those who might be permanently unable to work, to offer them a thorough multiprofessional, medical examination and, in cases where the criteria for the disability pension were fulfilled, to provide a certificate to support a disability pension application. The EDIPE-process was initiated by the employment authorities, who assessed the participant's eligibility on the basis of the records of health problems, limitations in working ability and duration of the unemployment period, which should be at least 1 year.

For this research the data was derived from the documents of the case history register of the EDIPE-project. The research register included 505 participants of the EDIPEevaluation in Tampere, Finland for the years 2001-2006. The documents consisted of medical records requested from primary and specialized health care and the medical examinations of the EDIPE -project. The research register is presented in more detail in our previous publication [23].

The psychiatric assessments in the EDIPE project were made by experienced psychiatrists. The diagnoses of MDD (F32.*) or recurrent MDD (F33.*) were set in clinical examination by adhering to the criteria of ICD-10 [24]. Before the clinical examination, the psychiatrist acquainted him/ herself thoroughly with the health records acquired from primary and specialized health care as well as with the health records produced in the multi-professional assessment conducted during the EDIPE -project. A total of 243 participants (48\% of the sample of 505 long-term unemployed) received a MDD-diagnosis. They comprised the sample of the present study. This sample was classified into those who, according to the documents acquired from health care, had been diagnosed as suffering from MDD prior to entering into EDIPE -project into 'the identified' $(n=101,42 \%)$ and those whose depression had not been diagnosed 'the unidentified' $(n=142,58 \%)$. This dichotomous variable was the outcome of the study.

The explanatory factor was duration of unemployment, which was handled as a discrete variable in the multivariate analyses and presented in quartiles (1-6, 7-10, 11-13 and 14-35 years) in bivariate analyses. The duration of unemployment refers to the continuous duration of the person being recorded in the employment office as an unemployed jobseeker before entering in the EDIPE project. The recorded unemployment period included also participation in active labour market policy measures, such as various courses or spells of subsidized re-employment.

Background variables were as follows: Age was set as a discrete variable in the multivariate analyses and categorized into four-classes in the bivariate analyses. Marital status was dichotomized to single (including unmarried, divorced 
and widowed) and married/cohabiting. Occupational status was trichotomized to unskilled and skilled manual workers and non-manual workers including entrepreneurs. The information on homelessness was self-reported, as was having a criminal record. The information on suicide attempts (yes or no) was gathered from the records of primary and specialized health care, as was the number visits to physicians during the preceding 3 years. The number of visits was handled as a discrete variable in multivariate analyses and categorized into four in the bivariate analyses.

After describing the associations between background factors and 'Identification of MDD', binomial logistic regression analyses were conducted with 'Identification of MDD' as the dependent variable and duration of unemployment, as a discrete variable, as the main explanatory variable. The analysis was adjusted separately for sociodemographic background variables, for variables with statistically significant difference for the identification of MDD in bivariate analyses, for variables associated to social exclusion and for variables associated with the using health care services. Finally, the whole set of variables was introduced into the regression model.

Pearson's Chi-square and Fisher's exact tests were used in the comparison of the categorical variables in bivariate analyses. In the regression models the association of the identification of MDD in health care with the duration of unemployment was described by odds ratios (OR) per 1 year of unemployment and corresponding $95 \%$ confidence intervals (CI). The statistical significance was determined with $\mathrm{p}$ value $<0.05$. Statistical analyses were conducted by SPSS/ Win software version 23, IBM $^{\mathrm{R}}$ SPSS $^{\mathrm{R}}$ statistics.

\section{Results}

Of the studied group of long-term unemployed diagnosed as depressed on the EDIPE-project, men accounted for $59 \%(n=144)$. The mean age was 52 years (SD 6.3, range 29-64 years). Single were 73\% $(n=178)$ and manual workers, skilled or unskilled, amounted for $82 \%(n=193)$. The unemployment had lasted for a very long time, on average 10 years (median 11 years, SD 5.7) and at maximum 35 years. Suicide attempts were found in the records of $20 \%$ $(n=49)$ of the participants. On an average 11 visits in health care were observed in the 3 years prior to the entry into the EDIPE-project (median 8, SD 10.7, range 0-89).

Of those 243 with diagnosed MDD, $8.6 \%$ suffered mild, $54.7 \%$ moderate, $21.4 \%$ severe, $0.8 \%$ psychotic depression and on $14.4 \%$ the severity of MDD remained unspecified. Recurrent episode of depression was discovered on $10.7 \%$ and psychiatric comorbidity occurred on $79 \%$ of participants. The most prevalent comorbidity, alcohol use disorder (AUD, containing ICD-codes F10.1 alcohol abuse and F10.2 alcohol dependence), was diagnosed on EDIPE-project on $49 \%$, personality disorder (F6*, according to ICD-10) on $38 \%$ and anxiety disorder (F4*, according to ICD-10) on $25 \%$ of the participants.

Descriptive statistics of the study population according to the identification of MDD are presented in Table 1. Nonidentification was associated with male gender $(p=0.047)$,

Table 1 Association of the background variables with the identification of major depressive disorder (MDD) in health care (HC)

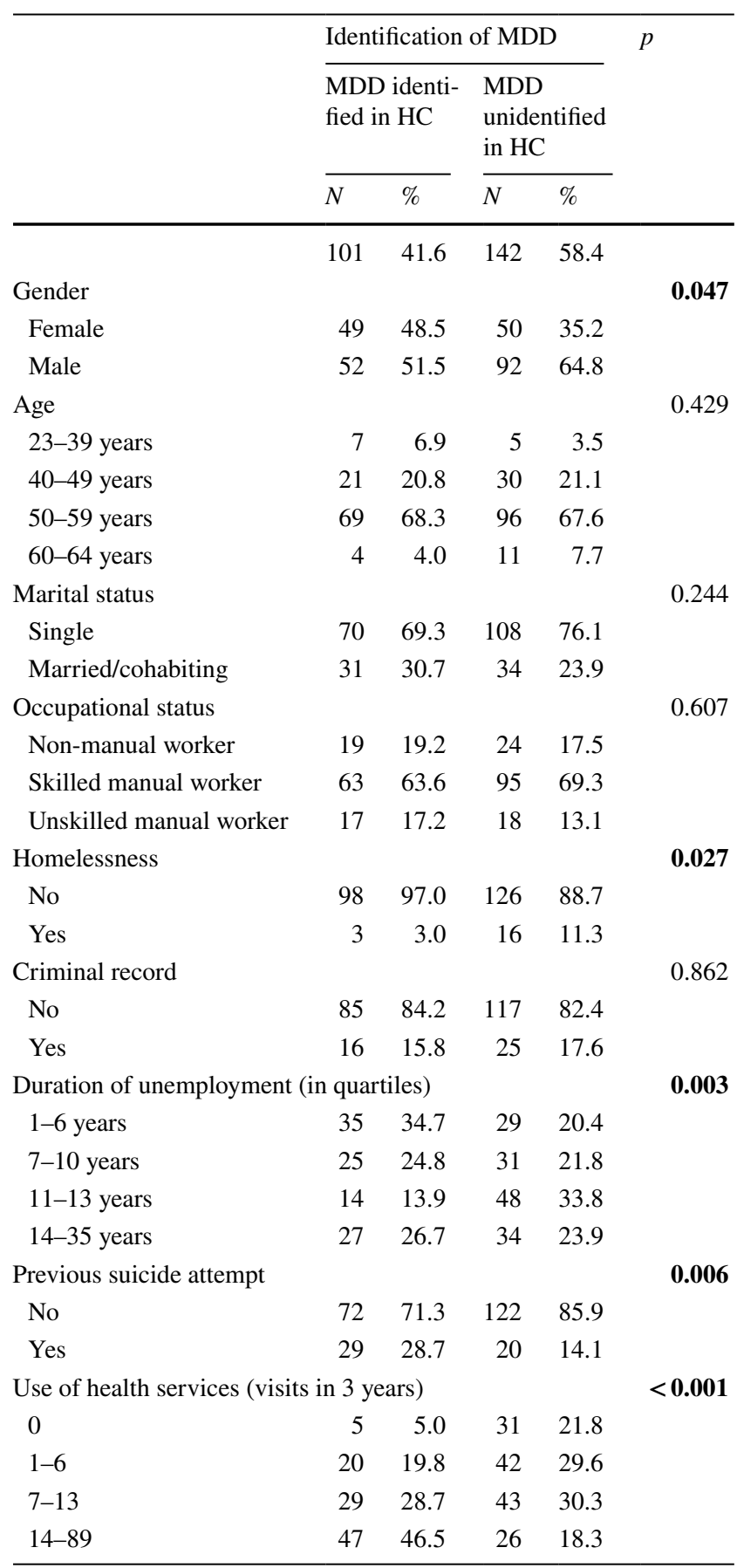

Bold values indicate statistically significant $(p<0.05)$ 
homelessness $(p=0.027)$ and longer duration of unemployment $(p=0.009)$. Previous suicide attempts $(p=0.006)$ and higher number of visits in health care $(p<0.001)$ were positively associated with the identification of MDD. Mean duration of unemployment was 11 years (SD 5.5) and 9 years (SD 5.9) among those with unidentified and identified MDD $(p=0.014)$, respectively. In addition, the identification of MDD in health care among homeless persons tended to remain lower than among those with a permanent residence ( 16 vs. $44 \%, p=0.027$ ). Furthermore, MDD was identified more commonly among subjects with suicide attempts (59 vs. $37 \%, p=0.006$ ). Of the whole study population $15 \%$ had not visited health care at all in the 3 years prior to participating in the EDIPE-project, $6 \%$ of women and $21 \%$ of men, and of those whose depression remained unidentified $22 \%$ had not used any health care services. The identification of MDD was more frequent when there had been at least 14 visits to health care during the last 3 years before the EDIPE -project compared to $1-6$ or $7-13$ visits, 64 vs. $32 \%$ and $40 \%$, respectively.

The health records revealed the information of ongoing and/or past mental health care as follows: of the study group, $59 \%$ were prescribed antidepressive medicine. The regular psychiatric treatment relationship in specialized mental health clinic had carried out on $14 \%$, but intensive psychotherapy got only 3\%. Psychiatric hospitalizations had 15\% of the study group. A treatment contact in the outpatient substance abuse services had met with $32 \%$ and in inpatient detoxification care $28 \%$.

Table 2 Association of the duration of unemployment, as discrete variable, with unidentified major depressive disorder (MDD) in health care (HC) in crude model and after adjusting for several multi-
In the binomial regression analysis (Table 2) the OR for unidentified MDD was $1.060(p=0.016)$ per 1 year of unemployment. This means a higher risk for unidentified MDD among those with longer duration of unemployment. If unemployment had continued 5 years the OR for unidentified MDD increased to 1.336 and after 10 years of unemployment to 1.786 . The binomial regression analyses were conducted to exclude potential confounders among factors associated to identification or non-identification of MDD in bivariate analyses. The result remained at the same level throughout adjustments: In Model 2 sociodemographic background variables (OR 1.056, $p=0.028$ ), in Model 3 for variables with statistically significant difference in the bivariate analyses from the identification of MDD (OR 1.057, $p=0.033$ ), in Model 4 for variables associated with social exclusion (OR 1.070, $p=0.009$ ), in Model 5 for variables associated with the use of health services (OR $1.062, p=0.022)$ and in Model 6 the full model for all the background variables in Models from 2 to 4 (OR 1.073, $p=0.012$ ).

\section{Discussion}

The study revealed that the diagnosis of MDD can be found in the documents of the health care in less than half of the long-term unemployed suffering from this disorder. Moreover, in the line with our expectations, the risk for

variate models described by odds ratios (OR) per 1 year of unemployment and $95 \%$ confidence intervals (CI)

\begin{tabular}{|c|c|c|c|}
\hline & $\begin{array}{l}\text { OR/1 year of } \\
\text { unemploy- } \\
\text { ment }\end{array}$ & CI & $p$ \\
\hline $\begin{array}{l}\text { Model } 1 \\
\text { Crude model }\end{array}$ & 1.060 & $1.011 ; 1.111$ & 0.016 \\
\hline $\begin{array}{l}\text { Model } 2 \\
\text { Adjusted for sociodemographic characteristics: Age, gender, marital status }\end{array}$ & 1.056 & $1.006 ; 1.108$ & $\mathbf{0 . 0 2 8}$ \\
\hline $\begin{array}{l}\text { Model } 3 \\
\text { Adjusted for variables with statistically significant difference from identification of MDD in bivariate } \\
\text { analyses: gender, homelessness, suicide attempts, number of visits to HC in last } 3 \text { years }\end{array}$ & 1.057 & $1.004 ; 1.113$ & $\mathbf{0 . 0 3 3}$ \\
\hline $\begin{array}{l}\text { Model } 4 \\
\text { Adjusted for variables related to social exclusion: gender, marital status, occupational status, homeless- } \\
\text { ness, criminal record }\end{array}$ & 1.070 & $1.017 ; 1.126$ & 0.009 \\
\hline $\begin{array}{l}\text { Model } 5 \\
\text { Adjusted for variables related to use of HC: Number of visits to HC, age, gender, suicide attempts }\end{array}$ & 1.062 & $1.009 ; 1.118$ & 0.022 \\
\hline Model 6 & 1.073 & $1.016 ; 1.135$ & 0.012 \\
\hline
\end{tabular}

Bold values indicate statistically significant $(p<0.05)$ 
unrecorded depression increased along with the duration of the unemployment.

The reason of missing records was naturally evident in the case of those 36 (15\%) individuals who had not used health care services during the preceding 3 years. The rest had 1-89 physician visits, and among these a record of depression was found in $46 \%$. This figure nearly falls within the wide range from 47 to $84 \%$ found in earlier studies for the identification of depression among primary health care patients by general practitioners (GP) $[14,15]$. Moreover, there is evidence that unemployment may be one background factor increasing the detection of depression by GPs [3, 25]. We also found that the number of visits was positively associated with a recording of depression, indicating in line with earlier research [26] that a proper diagnostics of depression requires multiple appointments.

The findings of this study need to be assessed in the light of the nature of the data. The study material was quite comprehensive, including not only primary health care documents but also documents from outpatient and inpatient care in specialized health services, including psychiatry, rehabilitation institutions and even the prison administration. Thus the identification rate of $42 \%$ is quite low. On the other hand, the use of the health services comprises most commonly different kinds of acute or subacute appointments, so it is conceivable that in the context of such an encounter it is not even relevant to raise and tackle potential mental health issues. This also applies to visits to specialized secondary health care. Secondly, the clinicians may have considered a patient's depressiveness and unemployment as a kind of complex that does not serve a starting point for diagnostic and therapeutic measures and have classified this more as a social problem. At the other extreme of the identification of depression there are those patients who had attempted suicide. As suicidality is closely connected to MDD as one serious symptom or complication of the syndrome, a previous suicide attempt increased the likelihood of MDD being diagnosed in health care. The result may refer to only observing and diagnosing MDD after it had become even more serious and complicated accompanied by suicidal intentions. There is evidence that recognition of depression is directly related to its severity [26]. The proportion of suicide attempts in the study population was $20 \%$, which is relatively high when compared to previous Finnish primary care studies on patients with MDD $(10-17 \%)[27,28]$.

We applied fairly strict criteria, requiring an explicit MDD diagnosis for a record to be valid and considered identification of MDD in the EDIPE-project as 'the gold standard'. These diagnoses were not standardized in the sense of a uniform procedure. However, the diagnoses were based on individual clinical interviews according to the ICD-10 criteria and extensive preliminary knowledge acquired by the experienced psychiatrists engaged on the EDIPE project.
In the other words, the 'standard' was EDIPE's overall interest in assessing the extent to which depression, alone or in combination with other psychiatric or somatic diseases, contributed to a patient's impaired work ability both present and future. This EDIPE scope and associated interrater incompatibility [29] may have contributed to but cannot be the major explanation for the huge discrepancy between health care recorded and EDIPE diagnosed prevalence of MDD. A more substantial, though not exhaustive, explanation may be that, as indicated in some earlier studies, recording of the diagnosis may be deficient in spite of appropriate recognition of MDD in health care [30, 31]. Moreover, in some cases the health care records may miss the diagnosis because MDD has appeared shortly before the entry or even during the EDIPE -process. The knowledge of functional capacity would complete the relevance of identification of depression, but, as a limitation, the information was not systematically recorded.

We argue that the long-term unemployed are marginalized from appropriate identification of MDD in health care. The argument is supported by the finding that the probability of unrecorded MDD was positively associated with the duration of unemployment. Moreover, this marginalization from health services seems to be a phenomenon of its own, as the association remained significant when a wide range of background variables, including other indicators of marginalization, were controlled for. Our findings add to and specify the body of knowledge showing use of health services as decreased and the unmet care needs as increased among the unemployed [16, 18, 21]. In particular, there are unmet needs for psychiatric care [20], for instance according to an Australian study, the unemployed are twice as likely to suffer from affective symptoms as the employed but they are less likely to consult a GP [17].

Reduced help seeking during unemployment can be explained as a low social pressure for recovery, which, furthermore, can be understood as reflecting lowered level of bonding social capital and consequent reduction in the use of health services [32]. But the reasons for scarce use of health care services and unmet care needs may also lie in the structures of health care. This viewpoint has a particular relevance in Finland: There is a widespread occupational health care system providing easily accessible and free of charge services exclusively for the employed population, whereas the services for the unemployed are limited to universal primary health care [33]. The findings of this study also give reasons to consider ways to improve the coverage and the content of health services among the unemployed.

There is some evidence that unemployment increases the risk for depression particularly among men [34]. Among older long-term unemployed men who were guided to a psychosocial coaching center, more than three quarters were found to suffer from mood disorders and 
$28 \%$ from depression or double depression [35]. However, in line with earlier research [36-38], women (54\%) got a diagnosis of MDD in the EDIPE -examinations more commonly than men (45\%). Among those with the diagnosis, women's MDD had been recorded in health care more often than men's (50 vs. $36 \%$ ); this is likely due to gender differences in the threshold to seek help for mental problems [39, 40].

The EDIPE-project was based on the assumption that among the hardest-core long-term unemployed there are many people who have chronic illnesses, who have been marginalized even from health services and whose work ability has not been appropriately assessed. The findings support this assumption: The project was successful in detecting a lot of MDD that had not been identified prior to entry into the EDIPE-examinations. The diagnosis contributed, solely or mostly in combination with other diagnoses, to the decision to apply for a disability pension. Future disability retirement or treatment were not in the scope of this study, which aimed to reveal the features of marginalization with depression as the indicator.

The long-term unemployed are often overrepresented in the groups of non-responders to surveys and dropouts in longitudinal studies [41-43]. Participation in the EDIPE -project was decided on the employment office based on discussion between the client and the counsellor specialized in disabled job seekers. The participants may be considered to represent the target group quite comprehensively or the long-term unemployed and disabled population. Moreover, the health records were collected comprehensively from registers of the existing institutions, both primary and specialized health care. A major strength of the study lies in the unique sample and data. But the uniqueness also means a limitation of generalizability. Because the findings describe the situation of the long-term unemployed with remarkable health and employability problems, the results may not be generalized into the unemployed population as a whole. Furthermore, the results are confidently generalizable in societies like Finland, which represents the Nordic welfare state.

In addition to demonstrating the extent of unidentified MDD among the long-term unemployed, this study showed, to the best of our knowledge for the first time, that identification is negatively associated with duration of the unemployment. The reasons for this evident neglect of MDD range from structures of the health services and practices of health care professionals to the help-seeking behavior of long-term unemployed individuals. Nevertheless, as a policy conclusion, attention should be paid to reducing the employment status related inequality embedded in the structures and in the practices of the health care system.

\section{Conclusions}

We concluded that more attention should be paid in health care to identifying MDD among the long-term unemployed as a risk group. The protracted unemployment period seems to be an independent risk factor for non-identification of MDD in health care. There were problems especially in the identification of MDD among long-term unemployed men. Moreover, the long-term unemployed men in the study did not actively seek help even for serious depression. Perhaps some kind of occupational health care system for unemployed could raise the identification rates and achieve adequate treatment for depression, which might even improve the chances for re-employment. A major reform of social and health care services is currently ongoing in Finland in an attempt to affirm the collaboration and streamline the health, social and welfare services [44]. Hopefully these prospective multi-sectoral changes will also improve the health services for the long-term unemployed.

Acknowledgements This work was supported by the National Graduate School of Clinical Investigation (CLIGS).

\section{Compliance with ethical standards}

Ethical standards The material of the study was based entirely on the record information and there were no personal contacts to the subjects of the study. The research was approved by the ethics committee of Pirkanmaa Hospital District, ETL-code R06032, and the registrar of the EDIPE-project. The manuscript does not contain clinical studies or patient data.

Conflict of interest The authors declare that they have no conflict of interest.

\section{References}

1. Vos T, Barber RM, Bell B, Bertozzi-Villa A, Biryukov S, Bolliger I et al (2013) Global, regional, and national incidence, prevalence, and years lived with disability for 301 acute and chronic diseases and injuries in 188 countries, 1990-2013: a systematic analysis for the global burden of disease study 2013. Lancet 386(9995):743-800

2. Wittchen HU, Jacobi F, Rehm J, Gustavsson A, Svensson M, Jönsson B et al (2011) The size and burden of mental disorders and other disorders of the brain in Europe 2010. Eur Neuropsychopharm 21(9):655-679

3. Wittchen H, Höfler M, Meister W (2001) Prevalence and recognition of depressive syndromes in German primary care settings: poorly recognized and treated? Int Clin Psychopharmacol 16(3):121-135

4. World Health Organization WHO (2016) Health statistics and information systems. Global health estimates. http://www.who. int/healthinfo/global_burden_disease/metrics_daly/en/. Accessed 12 Oct 2016

5. Salokangas RKR, Poutanen O, Stengård E, Jähi R, Palo-Oja $T$ (1996) Prevalence of depression among patients seen in 
community health centres and community mental health centres. Acta Psych Scand 93(6):427-433

6. Ansseau M, Fischler B, Dierick M, Albert A, Leyman S, Mignon A (2008) Socioeconomic correlates of generalized anxiety disorder and major depression in primary care: the GADIS II study (generalized anxiety and depression impact survey II). Depress Anxiety 25(6):506-513

7. Greenberg PE, Fournier A-, Sisitsky T, Pike CT, Kessler RC (2015) The economic burden of adults with major depressive disorder in the United States (2005 and 2010). J Clin Psychiat 76(2):155-162

8. Dooley D, Catalano R, Wilson G (1994) Depression and unemployment: panel findings from the epidemiologic catchment area study. Am J Commun Psychol 22(6):745-765

9. McKee-Ryan FM, Song Z, Wanberg CR, Kinicki AJ (2005) Psychological and physical well-being during unemployment: a metaanalytic study. J Appl Psychol 90(1):53-76

10. Gallo WT, Bradley EH, Dubin JA, Jones RN, Falba TA, Teng $\mathrm{H}$ et al (2006) The persistence of depressive symptoms in older workers who experience involuntary job loss: results from the health and retirement survey. J Gerontol Ser B Psychol Sci Soc Sci 61(4):S221-S228

11. Paul KI, Moser K (2009) Unemployment impairs mental health: meta-analyses. J Vocat Behav 74(3):264-282

12. Stankunas M, Kalediene R, Starkuviene S, Kapustinskiene V (2006) Duration of unemployment and depression: a cross-sectional survey in Lithuania. BMC Public Health 6:174

13. Butterworth P, Leach LS, Pirkis J, Kelaher M (2012) Poor mental health influences risk and duration of unemployment: a prospective study. Soc Psychiatry Psychiatr Epidemiol 47(6):1013-1021

14. Mitchell AJ, Rao S, Vaze A (2011) International comparison of clinicians' ability to identify depression in primary care: metaanalysis and meta-regression of predictors. Brit J Gen Pract 61(583):e72-e80

15. Piek E, Nolen WA, Van Der Meer K, Joling KJ, Kollen BJ, Penninx BWJH et al (2012) Determinants of (non-) recognition of depression by general practitioners: results of the Netherlands study of depression and anxiety. J Affect Disorders 138(3):397-404

16. Virtanen P (1993) Unemployment, re-employment and the use of primary health care services. Scand J Prim Health Care 11(4):228-233

17. Comino E, Harris E, Chey T, Manicavasagar V, Wall J, Davies $\mathrm{G}$ et al (2003) Relationship between mental health disorders and unemployment status in Australian adults. Aust NZ J Psychiat 37(2):230-235

18. Åhs A, Westerling R (2006) Health care utilization among persons who are unemployed or outside the labour force. Health Policy 10;78(2-3):178-193

19. Honkonen T, Virtanen M, Ahola K, Kivimäki M, Pirkola S, Isometsä E et al (2007) Employment status, mental disorders and service use in the working age population. Scand J Work Environ Health 33(1):29-36

20. Joska J, Flisher A (2005) The assessment of need for mental health services. Soc Psych Psych Epid 40(7):529-539

21. Åhs A, Burell G, Westerling R (2012) Care or not care-that is the question: Predictors of healthcare utilisation in relation to employment status. Int J Behav Med 19(1):29-38

22. Työministeriö [Ministry of Labour] (2004) Pitkäaikaistyöttömien eläkemahdollisuuksien selvittäminen (ELMA). Ohje O/2/2004 TM 2004 [Eligibility for a Disability Pension -project. Instruction O/2/2004 TM 2004]

23. Nurmela K, Heikkinen V, Hokkanen R, Ylinen A, Uitti J, Mattila A et al (2015) Identification of alcohol abuse and transition from long-term unemployment to disability pension. Scand J Public Health 43(5):518-524
24. World Health Organization WHO (2016) International statistical classification of diseases and related health problems 10th revision. http://apps.who.int/classifications/icd10/browse/2016/ en. Accessed 23 Sept 2016

25. Maginn S, Boardman AP, Craig TKJ, Haddad M, Heath G, Stott J (2004) The detection of psychological problems by general practitioners-influence of ethnicity and other demographic variables. Soc Psych Psych Epid 39(6):464-471

26. Menchetti M, Murri MB, Bertakis K, Bortolotti B, Berardi D (2009) Recognition and treatment of depression in primary care: effect of patients' presentation and frequency of consultation. J Psychosom Res 66(4):335-341

27. Vuorilehto MS, Melartin TK, Isometsä ET (2006) Suicidal behaviour among primary-care patients with depressive disorders. Psychol Med 36(2):203-210

28. Riihimäki K, Vuorilehto M, Melartin T, Haukka J, Isometsä E (2014) Incidence and predictors of suicide attempts among primary-care patients with depressive disorders: a 5-year prospective study. Psychol Med 44(2):291-302

29. Williams JW Jr, Noël PH, Cordes JA, Ramirez G, Pignone M (2002) Is this patient clinically depressed? J Am Med Assoc 287(9):1160-1170

30. Mitchell AJ, Vaze A, Rao S (2009) Clinical diagnosis of depression in primary care: a meta-analysis. Lancet 374(9690):609-619

31. Joling KJ, Van Marwijk HWJ, Piek E, Der Horst HEV, Penninx BW, Verhaak P et al (2011) Do GPs' medical records demonstrate a good recognition of depression? A new perspective on case extraction. J Affect Disord 133(3):522-527

32. Pitkin Derose K, Varda DM (2009) Social capital and health care access: a systematic review. Med Care Res Rev 66(3):272-306

33. Virtanen P, Kivimäki M, Vahtera J, Koskenvuo M (2006) Employment status and differences in the one-year coverage of physician visits: different needs or unequal access to services? BMC Health Serv Res 6:123

34. Economou M, Angelopoulos E, Peppou LE, Souliotis K, Stefanis C (2016) Major depression amid financial crisis in Greece: will unemployment narrow existing gender differences in the prevalence of the disorder in Greece? Psychiatry Res 242:260-261

35. Bühler B, Kocalevent R, Berger R, Mahler A, Preiß B, Liwowsky I et al (2013) Treatment situation of long-term unemployed with psychological disorders. Nervenarzt 84(5):603-607

36. Pirkola SP, Isometsä E, Suvisaari J, Aro H, Joukamaa M, Poikolainen K et al (2005) DSM-IV mood-, anxiety- and alcohol use disorders and their comorbidity in the Finnish general population. Results from the Health 2000 Study. Soc Psychiatry Psychiatr Epidemiol 40(1):1-10

37. De Graaf R, Ten Have M, Van Gool C, Van Dorsselaer S (2012) Prevalence of mental disorders and trends from 1996 to 2009. Results from the Netherlands mental health survey and incidence study-2. Soc Psychiatry Psychiatr Epidemiol 47(2):203-213

38. Markkula N, Suvisaari J, Saarni SI, Pirkola S, Peña S, Saarni S et al (2015) Prevalence and correlates of major depressive disorder and dysthymia in an eleven-year follow-up — results from the Finnish health 2011 survey. J Affect Disord 173:73-80

39. Susukida R, Mojtabai R, Mendelson T (2015) Sex differences in help seeking for mood and anxiety disorders in the national comorbidity survey-replication. Depress Anxiety 32(11):853-860

40. Yousaf O, Popat A, Hunter MS (2015) An investigation of masculinity attitudes, gender, and attitudes toward psychological helpseeking. Psychol Men Masc 16(2):234-237

41. Korkeila K, Suominen S, Ahvenainen J, Ojanlatva A, Rautava $\mathrm{P}$, Helenius $\mathrm{H}$ et al (2001) Non-response and related factors in a nation-wide health survey. Eur J Epidemiol 17(11):991-999

42. Søgaard AJ, Selmer R, Bjertness E, Thelle D (2004) The Oslo health study: the impact of self-selection in a large, populationbased survey. Int J Equity Health 3:3 
43. Drivsholm T, Eplov LF, Davidsen M, Jørgensen T, Ibsen H, Hollnagel $\mathrm{H}$ et al (2006) Representativeness in population-based studies: a detailed description of non-response in a Danish cohort study. Scand J Public Health 34(6):623-631
44. Ministry of Social Affairs and Health, Ministry of Finance of Finland (2017) Government reform packages: Health, social services and regional reform. http://alueuudistus.fi/en/frontpage. Accessed 22 Feb 2017 